\title{
Management of Women with Severe Preeclampsia by Different Regimens of Magnesium Sulfate
}

\author{
Abd EL Samea Hassan Khalifa, Mohamed Mohamed Farahat and Khaled Mustafa Alsaudi \\ Department of Obstetrics and Gynecology, Faculty of Medicine, Al-Azhar University \\ Corresponding author: Khaled Mustafa Alsaudi, Mobile: (+20)01153350100, E-Mail: kms_1200@live.com
}

\begin{abstract}
Background: Preeclampsia is serious syndrome that can affect human pregnancy causing serious complications. Preeclampsia is pregnancy-specific syndrome of reduced organ perfusion secondary to vasospasm and endothelial activation. Objective: The aim of our study was to assess the comparative effects of three regimens for the administration of the magnesium sulfate when used for the care of women with severe preeclampsia to determine the effective dose of magnesium sulfate in controlling cases with severe preeclampsia and prevention of eclampsia and to determine whether only loading dose of magnesium sulfate is effective in prevention of eclampsia or not.

Patients and methods: The study included 240 pregnant women presenting to the casualty unit diagnosed as cases of severe preeclampsia in the Obstetrics and Gynecology Department, Al-Azhar University Hospital and EL Mahalla General Hospital. A randomized controlled study that compared three regimens for administration of $\mathrm{MgSO}_{4}$ used for these cases. Results: There was no significant difference between occurrence of eclampsia in the three groups after either administration of loading dose of $\mathrm{MgSO}_{4}$ only or administration of loading dose with maintenance dose for 12 hours or maintenance dose for 24 hours in the studied patients.

Conclusion: Magnesium sulfate proved to cause many hemodynamic changes as it has vasodilator effect on maternal and fetal blood vessels. Magnesium sulfate should be given to all patients with severe preeclampsia.
\end{abstract}

Keywords: Preeclampsia, Magnesium Sulfate

\section{INTRODUCTION}

Preeclampsia is a common complication of pregnancy and occur in about 5-10\% of all pregnancies (1). Preeclampsia is defined as a development of hypertension $(140 / 90 \mathrm{~mm} \mathrm{Hg})$ and new onset of one or more of the, proteinuria (>300 $\mathrm{mg}$ of urinary protein in $24 \mathrm{~h}$ ), end organ dysfunction after 20 weeks of gestations and unfortunately is a major cause of maternal and fetal morbidity and mortality worldwide (2).

In view of recent studies that indicate a minimal relation between quantity of urinary protein and pregnancy outcome in preeclampsia, massive proteinuria (greater than $5 \mathrm{~g}$ ) has been eliminated from consideration of preeclampsia as severe. Also, because fetal growth restrictions is managed similarly in pregnant women with or without preeclampsia, it was removed as a finding indicating severe preeclampsia ${ }^{(3)}$.

In normal pregnancy, adequate uteroplacental perfusion depends on normal physiologic development of the placental vascular system through trophoblast invasion of the uterine spiral arteries. The placental vasculature is subsequently converted into a dilated, low-resistance system, through a process termed angiogenesis ${ }^{(4)}$.

Preeclampsia is thought to be the consequence of impaired trophoblastic invasion of the maternal spiral arteries ${ }^{(5)}$.

Magnesium sulfate is a drug of choice in preeclampsia as an anticonvulsant rather than an antihypertensive ${ }^{(6)}$. Regimens for administration of this drug have evolved over the years, but have not yet been formally evaluated ${ }^{(7)}$.

In past, $\mathrm{MgSO}_{4}$ was given according to Pritchard regime in which 5 grams of magnesium sulfate was administered four-hourly for 24 hours after loading with 14 grams. It was observed that many patients did not receive maintenance therapy due to fear of toxicity but they did not convulse any further ${ }^{(8)}$. On the basis of this observation, many studies were planned to compare the efficacy of loading dose of magnesium sulfate versus the standard regime in the management of preeclampsia to prevent fits ${ }^{(9)}$.

Ehrenberg and Mercer ${ }^{(9)}$ studied abbreviated postpartum magnesium administration in 200 women with mild preeclampsia. None of these women and none of the other cohort given the 24 hour magnesium infusion developed eclampsia.

Implementation of magnesium sulfate would be strengthened if guidelines and recommendations for practice could be based on reliable evidence about the comparative effects of alternative regimens.

\section{AIM OF THE WORK}

The aim of our study was to assess the comparative effects of three regimens for the administration of the magnesium sulfate when used for the care of women with severe preeclampsia to determine the effective dose of magnesium sulfate in controlling cases with severe preeclampsia and prevention of eclampsia and to determine whether only 
loading dose of magnesium sulfate is effective in prevention of eclampsia or not.

\section{PATIENTS AND METHODS}

This is a randomized controlled study that compared three regimens for administration of $\mathrm{MgSO}_{4}$ used for the cases of severe preeclampsia. The study included 240 pregnant women presenting to the casualty unit, in the Obstetrics and Gynecology Department, Al-Azhar University Hospital and EL Mahalla General Hospital, diagnosed as cases of severe preeclampsia.

The study was approved by the Ethics Board of Al-Azhar University.

\section{Inclusion criteria:}

All women with severe preeclampsia,

Severe blood pressure elevation: systolic blood pressure $\geq 160 \mathrm{mmHg}$ or diastolic blood pressure $>100 \mathrm{mmHg}$ on two occasions at least four hours apart while the patient is on bedrest.

\section{With one or more of the following criteria:}

- Symptoms of central nervous system dysfunction: new onset visual or cerebral dysfunction.

- Pulmonary edema.

- Hepatic abnormalities.

- Thrombocytopenia $<100,000 /$ microl.

\section{Exclusion criteria:}

- Pregnant women $<24$ weeks gestation.

- Pregnant women with mild preeclampsia, eclampsia.

- Pregnant women with history of chronic hypertension.

- Pregnant women with history of epilepsy.

- Pregnant women with diabetes or renal disease.

Methods:

1- Full history taking: include age, parity, date of last menstrual period, present history, past history, obstetric history and family history.

2- Examination

a. General

- Blood pressure: two blood pressure readings at least 4 hours apart were obtained.

- Chest and heart examinations.

- Edema was tested.

b. Abdominal examination: For edema, liver, spleen and loin.

c. Neurological and retinal examination

3- Laboratory Investigations

- Complete blood count (platelets count), bleeding time, clotting time.

- Liver enzymes (ALT, AST).
- Kidney functions (creatinine, creatinine clearance).

- Urine analysis (volume, proteinuria).

4- Ultra-sonographic study

Biometric measurement to assess gestational age, number of fetuses, congenital anomalies, placental abnormalities, placental location and development of IUGR assisted by Doppler study

5- All women took initial $\mathrm{MgSO}_{4}$ (6 grams of $\mathrm{MgSO}_{4}$ on $250 \mathrm{ml}$ Ringer's solution over 20 minutes by IV drip).

The sample was divided into three categories:-

- Category $\mathbf{A} \rightarrow 80$ patients who took only loading dose of $\mathrm{MgSO}_{4}$ (6 grams of $\mathrm{MgSO}_{4}$ on $250 \mathrm{ml}$ ringer solutions over 20 minutes) with no postpartum maintenance sulfate.

- Category B $\rightarrow 80$ patients given abbreviated doses of $\mathrm{MgSO}_{4}$ (4 grams of $\mathrm{MgSO}_{4}$ on $250 \mathrm{ml}$ ringer solution over 4 hours every 4 hours by IV drip only for 12 hours) in the postpartum period.

- Category C $\rightarrow 80$ patients given full dose of maintenance $\mathrm{MgSO}_{4}$ (4 grams of $\mathrm{MgSO}_{4}$ on 250 $\mathrm{ml}$ ringer solution over 4 hours every 4 hours by IV drip for 24 hours) in the postpartum period.

\section{Outcomes}

1) Maternal

\section{- Short term outcome}

Primary outcome:-

1. Convulsion rate.

2. Women who had at least one of the following: liver failure, renal failure, HELLP syndrome (hemolysis, elevated liver enzymes and low platelets) and pulmonary edema.

3. Side effects: such as respiratory depression, flushing, nausea or vomiting, problems at the injection site.

4. Treatment discontinued because of side effects or adverse effects.

\section{Secondary outcome}
1) Induction of labor
2) Duration of labor
3) Placental blood loss
4) Blood transfusion
5) Respiratory depression
6) Pulmonary edema

2) Fetal:

1. Fetal heart rate pattern during labor.

2. Apgar score at 5 minutes.

3. Intubation at place of delivery.

4. NICU admission.

5. Still birth, IUGR, neonatal death.

6. Birth weight, prematurity.

\section{- Long term complications}

1. Maternal death.

2. Admission and length of stay in highdependency unit. 
3. Poor blood pressure control.

4. Need for additional anticonvulsant.

\section{Technique of Blood Pressure Measurement:}

- For the measurement of maternal blood pressure, a mercury sphygmomanometer was used, with a cuff of $20 \times 60 \mathrm{~cm}$.

- The initial measurement for the diagnosis of severe preeclampsia was performed while the patient was being seated, holding her right arm at heart level, being considered the last value obtained.

- After loading dose of magnesium sulfate, new blood pressure measurement was performed. Diastolic pressure was determined by Korotkoff phase V. All measurements were performed by the same researcher.

\section{Statistical analysis}

Table 1: Demographic features of the studied patients.
Data were statistically described in terms of mean \pm standard deviation $( \pm S D)$, median and range, or frequencies (number of cases) and percentages when appropriate. Comparison of numerical variables between the study groups was done using one way analysis of variance (ANOVA) test.

For comparing categorical data, Chi square $\left(\chi^{2}\right)$ test was performed. Exact test was used instead when the expected frequency is less than 5 .

$p$ values less than 0.05 was considered statistically significant. All statistical calculations were done using computer program SPSS (Statistical Package for the Social Science; SPSS Inc., Chicago, IL, USA) release 15 for Microsoft Windows (2006).

\section{RESULTS}

240 patients were recruited for our study based on their presentation which was severe preeclampsia.

\begin{tabular}{|l|l|r|r|r|r|}
\hline Group & & Age & GA & SBP & \multicolumn{1}{|c|}{ DBP } \\
\hline \multirow{5}{*}{ A } & Mean & 26.75 & 35.75 & 162.00 & 104.13 \\
\cline { 2 - 6 } & N & 80 & 80 & 80 & 80 \\
\cline { 2 - 6 } & Std. Deviation & 5.262 & 2.857 & 19.448 & 11.550 \\
\cline { 2 - 6 } & Minimum & 17 & 28 & 100 & 60 \\
\cline { 2 - 6 } & Maximum & 40 & 40 & 210 & 120 \\
\cline { 2 - 6 } & Median & 28.00 & 37.00 & 160.00 & 110.00 \\
\hline \multirow{5}{*}{ B } & Mean & 26.56 & 35.91 & 162.50 & 105.06 \\
\cline { 2 - 6 } & N & 80 & 80 & 80 & 80 \\
\cline { 2 - 6 } & Std. Deviation & 4.986 & 2.93 & 14.884 & 10.296 \\
\cline { 2 - 6 } & Minimum & 18 & 28 & 120 & 80 \\
\cline { 2 - 6 } & Maximum & 42 & 39 & 200 & 120 \\
\cline { 2 - 6 } & Median & 27.00 & 37.00 & 160.00 & 110.00 \\
\hline \multirow{5}{*}{ C } & Mean & 26.64 & 35.59 & 161.13 & 100.25 \\
\cline { 2 - 6 } & N & 80 & 80 & 80 & 80 \\
\cline { 2 - 6 } & Std. Deviation & 5.151 & 2.680 & 16.913 & 13.869 \\
\cline { 2 - 6 } & Minimum & 16 & 28 & 110 & 50 \\
\cline { 2 - 6 } & Maximum & 39 & 40 & 200 & 120 \\
\cline { 2 - 6 } & Median & 28.00 & 36.00 & 160.00 & 100.00 \\
\hline & F & 0.062 & 0.366 & 0.251 & 4.543 \\
\cline { 2 - 6 } & P & 0.973 & 0.761 & 0.877 & $0.028 *$ \\
\cline { 2 - 6 } & P1 & 0.953 & 0.283 & 0.189 & $0.008 *$ \\
\cline { 2 - 6 } & P2 & 0.959 & 0.801 & 0.865 & 0.213 \\
\cline { 2 - 6 } & P3 & 0.650 & 0.432 & 0.384 \\
\hline
\end{tabular}

F: one way ANOVA

$\mathrm{P}$ : total intergroup significance

P1: Significance between Group A and Group B

P2: Significance between Group A and Group C

P3: Significance between Group B and Group C 
Table 2: Parity, mode of delivery and proteinuria of the studied patients.

\begin{tabular}{|c|c|c|c|c|c|c|c|}
\hline & & \multicolumn{3}{|c|}{ Group } & \multirow[t]{2}{*}{ Total } & \multirow[t]{2}{*}{ p value } \\
\hline & & & $\mathbf{A}$ & B & C & & \\
\hline \multirow[t]{4}{*}{ Parity } & \multirow[t]{2}{*}{ multigravida } & Count & 50 & 50 & 51 & 151 & \multirow[t]{4}{*}{0.98} \\
\hline & & $\begin{array}{l}\text { \% within } \\
\text { Group }\end{array}$ & $62.5 \%$ & $62.5 \%$ & $63.8 \%$ & $62.9 \%$ & \\
\hline & \multirow[t]{2}{*}{ primigravida } & Count & 30 & 30 & 29 & 89 & \\
\hline & & $\begin{array}{l}\text { \% within } \\
\text { Group }\end{array}$ & $37.5 \%$ & $37.5 \%$ & $36.3 \%$ & $37.1 \%$ & \\
\hline \multirow[t]{4}{*}{ MOD } & \multirow[t]{2}{*}{ CS } & Count & 35 & 43 & 45 & 123 & \multirow[t]{4}{*}{0.24} \\
\hline & & $\begin{array}{l}\text { \% within } \\
\text { Group }\end{array}$ & $43.8 \%$ & $53.8 \%$ & $56.3 \%$ & $51.3 \%$ & \\
\hline & \multirow[t]{2}{*}{ VD } & Count & 45 & 37 & 35 & 117 & \\
\hline & & $\begin{array}{l}\text { \% within } \\
\text { Group }\end{array}$ & $56.3 \%$ & $46.3 \%$ & $43.8 \%$ & $48.8 \%$ & \\
\hline \multirow[t]{6}{*}{ proteinuria } & \multirow[t]{2}{*}{+2} & Count & 1 & 2 & $\mathbf{0}$ & 3 & \multirow[t]{6}{*}{0.60} \\
\hline & & $\begin{array}{l}\text { \% within } \\
\text { Group }\end{array}$ & $1.3 \%$ & $2.5 \%$ & $0.0 \%$ & $1.3 \%$ & \\
\hline & \multirow[t]{2}{*}{+3} & Count & 46 & 50 & 51 & 147 & \\
\hline & & $\begin{array}{l}\text { \% within } \\
\text { Group }\end{array}$ & $57.5 \%$ & $62.5 \%$ & $63.8 \%$ & $61.3 \%$ & \\
\hline & \multirow[t]{2}{*}{+4} & Count & 33 & 28 & 29 & 90 & \\
\hline & & $\begin{array}{l}\% \text { within } \\
\text { Group }\end{array}$ & $41.3 \%$ & $35.0 \%$ & $36.3 \%$ & $37.5 \%$ & \\
\hline
\end{tabular}

MOD $\rightarrow$ mode of delivery or termination

$\mathrm{CS} \rightarrow$ caesarian section

$\mathrm{VD} \rightarrow$ vaginal delivery

As regarding parity, mode of delivery and proteinuria there was no significant difference within the studied groups

Table. 3: Comparison between occurrence of eclampsia after administration of $\mathrm{MgSO}_{4}$ in the studied patients.

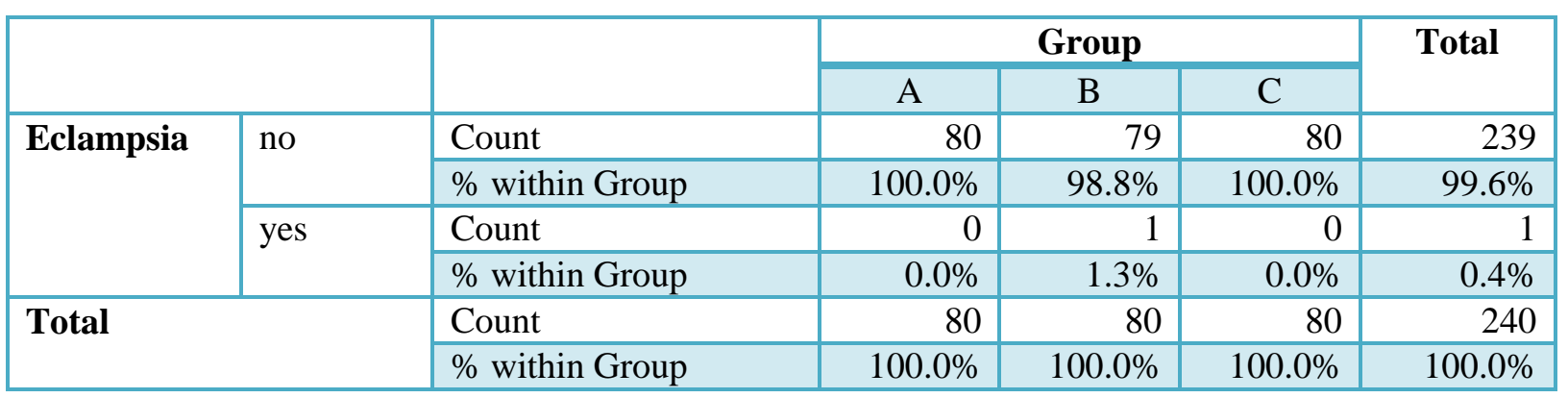

Data are expressed as frequency and percentage.

$\mathrm{P}=0.366=$ not significant.

There was no significant difference between occurrence of eclampsia in the three groups after either administration of loading dose of $\mathrm{MgSO}_{4}$ only or administration of loading dose with maintenance dose for 12 hours or 24 hours in the studied patients as shown in table 3 . 
Table 4: Comparison between development of HELLP syndrome in the studied groups after administration of $\mathrm{MgSO}_{4}$.

\begin{tabular}{|c|c|c|c|c|c|c|}
\hline & & \multicolumn{3}{|c|}{ Group } & \multirow[t]{2}{*}{ Total } \\
\hline & & & A & B & $\mathrm{C}$ & \\
\hline \multirow[t]{4}{*}{ HELLP } & \multirow[t]{2}{*}{ no } & Count & 78 & 77 & 75 & 230 \\
\hline & & $\%$ within Group & $97.5 \%$ & $96.3 \%$ & $93.8 \%$ & $95.8 \%$ \\
\hline & \multirow[t]{2}{*}{ yes } & Count & 2 & 3 & 5 & 10 \\
\hline & & $\%$ within Group & $2.5 \%$ & $3.8 \%$ & $6.3 \%$ & $4.2 \%$ \\
\hline \multirow{2}{*}{\multicolumn{2}{|c|}{ Total }} & Count & 80 & 80 & 80 & 240 \\
\hline & & \% within Group & $100.0 \%$ & $100.0 \%$ & $100.0 \%$ & $100.0 \%$ \\
\hline
\end{tabular}

Data are expressed as frequency and percentage.

$\mathrm{P}=0.482$ not significant.

There was no significant difference between occurrence of HELLP syndrome in the three groups after either administration of loading dose of $\mathrm{MgSO}_{4}$ only or administration of loading dose with maintenance dose for 12 hours or 24 hours in the studied patients

Table 5: Comparison between maternal side effects in the studied groups after administration of $\mathrm{MgSO}_{4}$

\begin{tabular}{|c|c|c|c|c|c|c|}
\hline & & \multicolumn{3}{|c|}{ Group } & \multirow{3}{*}{$\begin{array}{r}\text { Total } \\
24 \\
\end{array}$} \\
\hline & & & A & B & $\mathrm{C}$ & \\
\hline \multirow{4}{*}{$\begin{array}{l}\text { maternal } \\
\text { Side effect }\end{array}$} & \multirow[b]{2}{*}{ flushing } & Count & 8 & 5 & 11 & \\
\hline & & $\%$ within Group & $10.0 \%$ & $6.25 \%$ & $13.8 \%$ & $10 \%$ \\
\hline & \multirow[t]{2}{*}{ no } & Count & 72 & 75 & 69 & 216 \\
\hline & & $\%$ within Group & $90.0 \%$ & $93.75 \%$ & $86.3 \%$ & $90 \%$ \\
\hline \multirow{2}{*}{\multicolumn{2}{|c|}{ Total }} & Count & 80 & 80 & 80 & 240 \\
\hline & & $\%$ within Group & $100.0 \%$ & $100.0 \%$ & $100.0 \%$ & $100.0 \%$ \\
\hline
\end{tabular}

Data are expressed as frequency and percentage.

$\mathrm{P}=0.286$ not significant.

There was no significant difference between maternal side effects in the three groups after either administration of loading dose of $\mathrm{MgSO}_{4}$ only or administration of loading dose with maintenance dose for 12 hours or 24 hours in the studied patients

Table 6: Comparison between Neonatal ICU admission in the outcome of pregnancy in the studied groups after administration of $\mathrm{MgSO} 4$

\begin{tabular}{|c|c|c|c|c|c|c|}
\hline & & & \multicolumn{3}{|c|}{ Group } & \multirow[t]{2}{*}{ Total } \\
\hline & & & A & B & $\mathrm{C}$ & \\
\hline \multirow[t]{5}{*}{ NICU } & \multirow[t]{2}{*}{ no } & Count & 62 & 65 & 62 & 189 \\
\hline & & $\%$ within Group & $77.5 \%$ & $81.2 \%$ & $77.3 \%$ & $78.75 \%$ \\
\hline & \multirow[t]{3}{*}{ yes } & Count & 18 & 15 & 18 & 51 \\
\hline & & $\%$ within Group & $22.5 \%$ & $18.8 \%$ & $22.5 \%$ & $21.25 \%$ \\
\hline & & Count & 80 & 80 & 80 & 240 \\
\hline \multicolumn{2}{|l|}{ Total } & $\%$ within Group & $100.0 \%$ & $100.0 \%$ & $100.0 \%$ & $100.0 \%$ \\
\hline
\end{tabular}

Data are expressed as frequency and percentage.

$\mathrm{P}=0.799=\mathrm{NS}=$ not significant.

There was no significant difference between Neonatal ICU admission for the outcome of pregnancy in the three groups after either administration of loading dose of $\mathrm{MgSO}_{4}$ only or administration of loading dose with maintenance dose for 12 hours or 24 hours in the studied patients 
Table 7: Comparison between maternal ICU admission in the studied groups after administration of $\mathrm{MgSO}_{4}$

\begin{tabular}{|c|c|c|c|c|c|c|}
\hline & & \multicolumn{3}{|c|}{ Group } & \multirow[t]{2}{*}{ Total } \\
\hline & & & A & B & $\mathrm{C}$ & \\
\hline \multirow[t]{4}{*}{ MICU } & \multirow[t]{2}{*}{ no } & Count & 73 & 66 & 50 & 189 \\
\hline & & $\%$ within Group & $91.3 \%$ & $82.5 \%$ & $62.5 \%$ & $78.8 \%$ \\
\hline & \multirow[t]{2}{*}{ yes } & Count & 7 & 14 & 30 & 51 \\
\hline & & $\%$ within Group & $8.8 \%$ & $17.5 \%$ & $37.5 \%$ & $21.3 \%$ \\
\hline \multirow{2}{*}{\multicolumn{2}{|c|}{ Total }} & Count & 80 & 80 & 80 & 240 \\
\hline & & $\%$ within Group & $100.0 \%$ & $100.0 \%$ & $100.0 \%$ & $100.0 \%$ \\
\hline
\end{tabular}

Data are expressed as frequency and percentage.

$\mathrm{P}^{*}<0.0001^{*}=$ highly significant.

There was a significant difference between maternal ICU admission in the three groups after either administration of loading dose of $\mathrm{MgSO} 4$ only or administration of loading dose with maintenance dose for 12 hours or 24 hours in the studied patients where group $\mathrm{C}$ showing the highest rate for ICU admission while group A showing the lowest rate for ICU admission.

Table 8: Comparison between maternal ICU admission in the group A vs group B, group B vs group C and group A vs group $\mathrm{C}$ after administration of $\mathrm{MgSO}_{4}$

\begin{tabular}{|c|c|c|c|c|c|c|c|c|c|c|c|}
\hline & & \multicolumn{2}{|c|}{ Group } & \multirow[t]{2}{*}{ Total } & \multicolumn{2}{|c|}{ Group } & \multirow[t]{2}{*}{ Total } & \multicolumn{2}{|c|}{ Group } & \multirow[t]{2}{*}{ Total } \\
\hline & & & A & B & & B & $\mathrm{C}$ & & A & C & \\
\hline \multirow[t]{4}{*}{ MICU } & \multirow[t]{2}{*}{ no } & Count & 73 & 66 & 139 & 66 & 50 & 116 & 73 & 50 & 123 \\
\hline & & $\begin{array}{l}\% \text { within } \\
\text { Group }\end{array}$ & $91.3 \%$ & $82.5 \%$ & $86.9 \%$ & $82.5 \%$ & $62.5 \%$ & $72.5 \%$ & $91.3 \%$ & $62.5 \%$ & $76.9 \%$ \\
\hline & \multirow[t]{2}{*}{ yes } & Count & 7 & 14 & 21 & 14 & 30 & 44 & 7 & 30 & 37 \\
\hline & & $\begin{array}{c}\% \text { within } \\
\text { Group }\end{array}$ & $8.8 \%$ & $17.5 \%$ & $13.1 \%$ & $17.5 \%$ & $37.5 \%$ & $27.5 \%$ & $8.8 \%$ & $37.5 \%$ & $23.1 \%$ \\
\hline \multicolumn{3}{|c|}{ p value } & \multicolumn{3}{|c|}{0.101} & \multicolumn{3}{|c|}{0.005} & \multicolumn{3}{|c|}{0.0001} \\
\hline
\end{tabular}

Data are expressed as frequency and percentage.

In more detailed analysis of the significant difference between groups, we found that maternal ICU admission was highly significant between Group A and Group C and non-significant between Group A and B as Group A shows the lowest percentage in maternal ICU admission while Group $\mathrm{C}$ shows the highest maternal ICU admission with $\mathrm{P}$ value less than .0001 which is highly significant.

\section{DISCUSSION}

Preeclampsia is a major cause of perinatal and maternal morbidity and mortality, which affects 5-10 $\%$ of pregnancies ${ }^{(\mathbf{1})}$. There is strong evidence from many randomized trials that supports the use of magnesium sulfate for the prevention and treatment of women with eclampsia. The incidence of seizures in untreated preeclamptic women is approximately $3-4 \%$, whilst for those receiving magnesium sulfate; the rate is $0.8-1 \%$. There is little reliable evidence from randomized trials assessing the comparative effects of alternative routes of administration (intravenous or intramuscular), or the ideal duration of therapy ${ }^{(\mathbf{1 0})}$.

In our study we tried to compare three regimens of administration of magnesium sulfate where 240 patients were recruited and divided into three groups. Each group contains 80 patients, the first group received only the loading dose of $\mathrm{MgSO}_{4}$ and the second group received loading dose plus 12 hours maintenance dose while the last group received the loading dose and the full maintenance dose of $\mathrm{MgSo}_{4}$ for 24 hours.

We found that there was no significant difference between occurrence of eclampsia, HELLP syndrome, maternal side effects or prematurity and perinatal mortality and neonatal ICU admission in the three groups after either administration of loading dose of $\mathrm{MgSO}_{4}$ only or administration of loading dose with maintenance dose for 12 hours or 24 hours in the studied patients.

However, there was a significant difference between maternal ICU admissions in the three groups (Group A, B and C) with highest rate in Group C and lowest rate in Group A. Previous studies have attempted to limit $\mathrm{MgSO}_{4}$ infusion time after delivery. Shoaib et al. ${ }^{(11)}$, conducted their study on 100 women, 
50 were given only bolus dose of magnesium sulfate and 50 were given the standard regime. All women with severe preeclampsia and impending eclampsia were included in the study. Patients with pregnancy induced hypertension and mild to moderate preelampsia were excluded. 50 as A group were given only bolus dose of magnesium sulfate and 50 as B group were given the standard regime. They were observed for one week for the number of convulsions. They found that there was no significant difference in the two groups in term of occurrence of seizures, one patient developed fit with Pritchard regimen. The rate of caesarean section was lower in group A, $12 \%$ versus $30 \%$ in group $B(p=0.05)$. There was no significant difference in perinatal outcome in either group. The result of this study is similar to our study. However, in our study we conducted the study in 240 patients dividing them in three groups considering the abbreviated regimen in our study.

Omkara et al. ${ }^{(12)}$, conducted their study on 170 cases divided into two groups. 85 cases in each group. Each group had 50 eclampsia cases and 35 imminent eclampsia cases. The groups were compared with respect to age, gravidity antihypertensive therapy, gestational age, antenatal care, type of eclampsia, need and dose of $\mathrm{MgSO}_{4}$ received, complications during $\mathrm{MgSO}_{4}$ therapy and finally concluded that low dose magnesium sulfate is as standard regime with lesser side effects and equally good perinatal outcome. In our study we considered only cases with severe preeclampsia and we excluded cases with eclampsia.

Fontenot et al. ${ }^{(13)}$ conducted their study on 98 women (mean age $~ 24$ years, $53 \%$ primigravida) with severe preeclampsia, needing $\mathrm{MgSO}_{4}$ postpartum. They found that postpartum diuresis is an indicator of a low need to reinitiate treatment by $\mathrm{MgSO}_{4}$ for recurrent disease. We didn't consider diuresis as an indicator for stopping $\mathrm{MgSO}_{4}$ doses.

Chissell et al. ${ }^{(14)}$ made a small trial of women with severe preeclampsia or imminent eclampsia and compared a high dose intravenous regimen of $6 \mathrm{~g}$ IV loading dose followed by $2 \mathrm{~g}$ per hour by intravenous infusion with the standard intramuscular regimen of 4 $\mathrm{g}$ IV plus $10 \mathrm{~g}$ IM loading dose, and $5 \mathrm{~g}$ every four hours for maintenance therapy. The result of this study is similar to our study. However, in our study we conducted the study in larger number of cases (240 patients) dividing them in three groups considering the abbreviated regimen in our study.

Other studies were conducted on women with eclampsia comparing the loading dose versus the standard regimen for $\mathrm{MgSO}_{4}$ with similar outcome.

Regmi et al. ${ }^{(15)}$ studied 80 eclamptic women who were randomized to receive either standard Pritchard regimen (loading and maintenance) or loading dose of magnesium sulfate. Both groups were evaluated for recurrence of seizures and outcomes. They found that loading dose of magnesium sulfate is a good alternative for standard Pritchard regimen. It avoids multiple painful injections of magnesium Sulfate.

Bhattacharjee et al. ${ }^{(16)}$ studied 144 women with eclampsia who were divided into a study group and a control group of 72 women each. The study group received $0.75 \mathrm{~g} / \mathrm{h}$ of magnesium sulfate intravenously after a loading intravenous dose of $4 \mathrm{~g}$ and the control group was given the standard intramuscular regimen as advocated by Pritchard. They found that low-dose intravenous magnesium sulfate was found to be as effective as the standard intramuscular regimen, while maintaining a high safety margin.

\section{CONCLUSION}

- Preeclampsia constitutes a serious problem with high incidence that faces the workers in the field of obstetrics and needs good diagnosis and management and must not be neglected as maternal and fetal morbidity and mortality are so dangerous.

- The early diagnosis of severe preeclampsia is very important in order to minimize maternal and fetal complications.

- We must put the risk factors of preeclampsia in our mind when history is taken and during examination of pregnant females in order not to misdiagnose the cases of preeclampsia.

- Clinical examination of pregnant females with preeclampsia should be supported and confirmed by laboratory investigations and ultra-sonography to detect complications and for assessment of fetal well-being.

- Magnesium sulfate proved to cause many hemodynamic changes as it has vasodilator effect on maternal and fetal blood vessels. Magnesium sulfate should be given to all patients with severe preeclampsia.

- Considering the equal effectiveness, fewer side effects, ease of monitoring and cost-effectiveness of loading dose, single loading dose of magnesium sulfate in the management of preeclampsia is preferable to other regimes of administration requiring multiple doses.

\section{RECOMMENDATIONS}

- We recommend the use of loading dose only of $\mathrm{MgSO}_{4}$ in the antepartum period with no postpartum maintenance doses. If complications occurred, we recommend the abbreviated regimen as an alternative to the standard regimen.

\section{REFERENCES}


1. Steegers EA, von Dadelszen P, Duvekot PR et al. (2010): Pre-eclampsia. The Lancet, 376(9741): 631644.

2. Davison JM, Homuth V, Jeyabalan A et al. (2004): New aspects in the pathophysiology of preeclampsia. Journal of the American Society of Nephrology, 15(9): 2440-2448.

3. American College of Obstetricians and Gynecologists (2013): hypertension in pregnancy. Report of the American College of Obstetricians and Gynecologists' Task Force on Hypertension in Pregnancy. Obstetrics and gynecology, 122(5): 11221129.

4. Sultana Z, Maiti K, Aitken J et al. (2017): Oxidative stress, placental ageing related pathologies and adverse pregnancy outcomes. American Journal of Reproductive Immunology, 77(5): 12653-12655.

5. Labarrere CA, DiCarlo HL, Bammerlin E et al. (2017): Failure of physiologic transformation of spiral arteries, endothelial and trophoblast cell activation, and acute atherosis in the basal plate of placenta. American Journal of Obstetrics and Gynecology, 216(3): 287-1.

6. Guzin K, Goynumer G, Gokdagli F et al. (2010): The effect of magnesium sulfate treatment on blood biochemistry and bleeding time in patients with severe preeclampsia. The Journal of Maternal-Fetal \& Neonatal Medicine, 23(5): 399-402.

7. Dhakal G, Subedi $M$ and Paudel, $K$ (2012): Magnesium sulphate in management of severe preeclampsia and eclampsia. Journal of Nepal Health Research Council, 10(21): 113-117.

8. Tukur, J (2009): The use of magnesium sulphate for the treatment of severe pre-eclampsia and eclampsia. Annals of African Medicine, 8(2):16-19.

9. Ehrenberg HM and Mercer BM (2006): Abbreviated postpartum magnesium sulfate therapy for women with mild preeclampsia: a randomized controlled trial. Obstetrics \& Gynecology, 108(4): 833-838.

10. Duley L, Henderson-Smart DJ, Walker GJ et al. (2010): Magnesium sulphate versus diazepam for eclampsia. Cochrane Database of Systematic Reviews, 12:19-23.

11. Shoaib T, Khan S, Javed I et al. (2009): Loading Dose of Magnesium Sulphate Versus Standard Regime for Prophylaxis of Pre-eclampsia. Journal of the College of Physicians and Surgeons Pakistan, 19 (1): 30-33

12. Omkara M, Shobha BS, Dhananjaya SS et al. (2013): A comparative study of low dose magnesium sulphate regime and pritchard regime for imminent eclampsia and eclampsia. Int J Biol Med Res., 4(2) :3001- 3004

13. Fontenot MT, Lewis DF, Frederick JB et al. (2005): A prospective randomized trial of magnesium sulfate in severe preeclampsia: use of diuresis as a clinical parameter to determine the duration of postpartum therapy. American Journal of Obstetrics and Gynecology, 192(6): 1788-1793.

14. Chissell S, Botha JH, Moodley J et al. (1994): Intravenous and intramuscular magnesium sulphate regimens in severe pre-eclampsia. South African Medical Journal, 84(9): 607-610.

15. Regmi MC, Aggrawal A, Pradhan T et al. (2010): Loading dose versus standard regimen of magnesium sulphate in eclampsia- a randomized trial. Nepal Med Coll J., 12(4), 244-7.

16. Bhattacharjee N, Saha SP, Ganguly RP et al. (2011). A randomised comparative study between low-dose intravenous magnesium sulphate and standard intramuscular regimen for treatment of eclampsia. Journal of Obstetrics and Gynaecology, 31(4): 298-303. 